\title{
Relationship Between Alcohol Consumption and Prostatic Hyperplasia According to Facial Flushing After Drinking in Korean Men
}

\author{
Hak Sun Jang, Jong Sung Kim*, Sung Soo Kim, Jin-Gyu Jung, Seok-Joon Yoon, HyunJu Yang, Hyun Chul Joung \\ Department of Family Medicine, Research Institute for Medical Sciences, Chungnam National University School of Medicine, Daejeon, Korea
}

\begin{abstract}
Background: The purpose of this study was to examine whether facial flushing after drinking influences the relationship between alcohol consumption and prostatic hyperplasia among Korean men.

Methods: The subjects were 957 Korean men (180 non-drinkers, 389 with drinking-related facial flushing, 388 without facial flushing) in the 40-69 age group, who underwent prostate ultrasound at the health promotion center of Chungnam National University Hospital between 2008 and 2014. Alcohol consumption and alcohol-related facial flushing were assessed through a questionnaire. In terms of the amount consumed, $14 \mathrm{~g}$ of alcohol was considered a standard drink. With the non-drinker group as reference, logistic regression was used to analyze the relationship between weekly alcohol intake and prostatic hyperplasia in the flushing and non-flushing groups, with adjustment for confounding factors such as age, body mass index, smoking, and exercise patterns.

Results: Individuals aged 50-59 years who experienced drinking-related facial flushing had a significantly lower risk of prostatic hyperplasia than the non-drinker group, depending on alcohol consumption: $\leq 4$ standard drinks (adjusted odds ratio [OR], 0.38; 95\% confidence interval [CI], 0.16 to 0.86 ); $>4 \leq 8$ standard drinks (OR, $0.35 ; 95 \% \mathrm{CI}$, 0.13 to 0.95 ); $>8$ standard drinks (OR, $0.33 ; 95 \% \mathrm{CI}, 0.13$ to 0.84 ). However, no significant relationship was observed between the number of drinks consumed and the risk of prostate hyperplasia in the non-flushing group.

Conclusion: The risk of prostatic hyperplasia appears to be reduced by alcohol consumption among Korean men aged 50-59 years who exhibit drinking-related facial flushing.
\end{abstract}

Keywords: Alcohols; Flushing; Prostatic Hyperplasia; Risk 


\section{INTRODUCTION}

Prostatism refers to the enlargement of the prostate, also known as benign prostatic hyperplasia, and is pathologically diagnosed as prostatic stromal cell or epithelial cell proliferation. This condition is closely associated with aging. According to Western studies, $40 \%-70 \%$ of the male population aged $\geq 60$ years are affected. ${ }^{1)}$ In Korea, $22 \%$ of men aged $\geq 50$ years have lower urinary tract symptoms related to benign prostatic hyperplasia, which lowers their quality of life. ${ }^{2)}$ Because of the increasing interest in the quality of life among the aging population, benign prostatic hyperplasia has gained importance as a national health issue. Therefore, many studies are under way to investigate the prevalence, cause, and risk factors of benign prostatic hyperplasia in Korea at the community level.

According to a study recently conducted in local communities in Korea, the prevalence of benign prostatic hyperplasia was $36 \%$ for men in their 60 s, $43 \%$ for men in their 70 s, and $53 \%$ for men in their 80 s. The prevalence after adjusting for age was $42 \%$, indicating that the prevalence of benign prostatic hyperplasia had increased compared to that reported in previous studies. ${ }^{3)}$ Some epidemiologic studies have suggested that metabolic syndrome, with clinical features of insulin resistance, lipid metabolism abnormalities, hypertension, and abdominal obesity, appears more frequently in patients with benign prostatic hyperplasia than in unaffected men of the same age group. ${ }^{4,5)}$ Platz et al. ${ }^{6}$ reported that the risk of benign prostatic hyperplasia was lower in those who consumed an appropriate amount of alcohol (30.1-50.0 g/ d). Similarly, in Korea, Lee et al. ${ }^{7)}$ conducted a study on 514 Korean men and confirmed an inverse relationship between alcohol consumption and benign prostatic hyperplasia.

Although the precise mechanisms underlying this relationship have not yet been elucidated, it is believed that blood estrogen level increases with the quantity of alcohol consumed, while androgen and testosterone levels decrease, ultimately reducing the risk of benign prostatic hyperplasia. $^{8,9)}$

Since alcohol metabolism depends on a genetic polymorphism of the aldehyde dehydrogenase 2 (ALDH2) gene, the amount of acetaldehyde produced by the action of ALDH2 is different for each individual, even if the same amount of alcohol is consumed. Most alcohol is broken down through the oxidative pathway where ADH and ALDH2 react. ALDH2 is a protein isoform of aldehyde dehydrogenase, which exists in mitochondria. The $A L D H 2$ polymorphism known as $A L D H 2 * 2$ is common in Northeast Asians, ${ }^{10)}$ and this $A L D H 2$ polymorphism results in low enzyme activity.

A recent study reported that $A L D H 2$ is related to chronic age-associated diseases such as coronary artery disease and hypertension. ${ }^{11)}$ Seok et al, ${ }^{12)}$ conducted a study on the relationship between missense ALDH2 (SNP: Glu504Lys) and benign prostatic hyperplasia in Koreans.

Facial flushing and various unpleasant physiological responses can occur after alcohol consumption. Alcohol-induced facial flushing occurs because of a lack of the ALDH2 enzyme, which is one of the iso- enzymes of ALDH. ${ }^{13)}$ However, no studies have been reported so far on the association between facial flushing and prostatic hyperplasia. Accordingly, this study investigated whether the relationship between the amount of alcohol consumption and prostatic hyperplasia is different for drinkers with and without facial flushing.

\section{METHODS}

\section{Study Subjects}

This study was conducted on men aged between 40 and 70 years who underwent prostate ultrasonography at the health examination center of Chungnam National University Hospital between January 2008 and October 2014. Of 986 patients, 11 who had recently been diagnosed with benign prostatic hyperplasia and prostatitis, eight who were receiving treatment for benign prostatic hyperplasia or hair loss, and 10 who did not answer the survey related to alcohol were excluded. Finally, 957 men participated in this study. The study was approved by the institutional review of board of Chungnam National University Hospital (IRB no.: 2015-09-009).

\section{Study Methods}

The size of the prostate (in grams) was confirmed through prostate ultrasonography during the health examination. Previous studies used various criteria for the epidemiologic definition of benign prostatic hyperplasia and its size, such as prostatic symptoms, digital rectal examination, the volume on prostate ultrasonography, and uroflowmetry. This study defined prostatic hyperplasia as the presence of a prostate that exceeded $20 \mathrm{~g}$, based on Garraway et al. ${ }^{14)}$

Alcohol consumption habits, smoking habits, amount of exercise, and presence of facial flushing after consuming alcohol were investigated through self-administered questionnaires, after which primary physicians performed interviews. The study subjects were divided into groups based on their age: those in their 40s, 50s, and 60s. They were also categorized into drinkers and non-drinkers, and the drinkers were sub-categorized into those with and without flushing (flushing and non-flushing group).

Height $(\mathrm{m})$ and weight $(\mathrm{kg})$ were measured with an automatic height-weight measuring device, and height $(\mathrm{m})$ was divided by the square of weight $(\mathrm{kg})$ to calculate the body mass index (BMI). For smoking habits, subjects were divided into those who had never smoked, those who had smoked in the past, and those who were currently smoking. For exercise habits, subjects were classified into four groups depending on whether they performed medium-to-high intensity exercise for longer than 30 minutes: those who did not work out; those who worked out irregularly (once or twice per week); those who worked out regularly (three to five times per week); and those who worked out almost every day.

\section{Statistical Analysis}

The demographic characteristics of the non-drinkers, flushing, and non-flushing groups were expressed as mean \pm standard deviation. T- 
tests were conducted to compare the age, BMI, and prostate size, while the chi-square test was used to compare smoking and amount of exercise, with non-drinkers being the control group.

The flushing and non-flushing groups were divided into three subgroups based on the amount of alcohol consumption per week: $\leq 4$ standard drinks, $>4 \leq 8$ standard drinks, and $>8$ standard drinks. In order to determine the relationship between the amount of alcohol consumption, flushing status, and prostatic hyperplasia, multivariate logistic regression was used to investigate the relative risk of prostatic hyperplasia in the subgroups in relation to the amount of alcohol consumed, after adjustment for other variables (age, BMI, amount of exercise, smoking habits) based on the non-drinker group. $\mathrm{P}<0.05$ was considered to be statistically significant, and IBM SPSS ver. 21.0 (IBM Corp., Armonk, NY, USA) was used for the statistical analyses.

\section{RESULTS}

\section{General Characteristics and Alcohol-Related Characteristics of the Study Subjects}

Among the 957 subjects, 180 were included in the non-drinker group, 389 in the flushing group, and 388 in the non-flushing group. The age of the subjects was $54.8 \pm 7.6$ years in the non-drinkers group, 52.0 \pm 7.5 years in the flushing group, and 51.1 \pm 6.9 years in the non-flushing group, indicating that the age of the drinkers in both the flushing $(\mathrm{P}<0.001)$ and non-flushing groups $(\mathrm{P}<0.001)$ was significantly lower than that of the non-drinkers.

The proportion of smokers was significantly higher among drinkers, in both the flushing $(\mathrm{P}<0.01)$ and the non-flushing group $(\mathrm{P}<0.01)$ as compared to non-drinkers: non-drinker group $23.9 \%$ ( $n=43)$, flushing group $33.7 \%$ ( $n=131)$, non-flushing group $34.8 \%(n=135)$. The prostatic size (gram) measured by ultrasonography was significantly smaller in the drinkers with facial flushing $(\mathrm{P}<0.01)$ and without facial flushing $(\mathrm{P}<0.01)$ than in the non-drinkers. BMI and exercise habits were not significantly different in the flushing and non-flushing groups compared to the non-drinker group (Table 1).

\section{Risk of Prostatic Hyperplasia by Age Group Based on the Amount of Alcohol Consumption in the Flushing Group}

Twenty-nine (64.4\%) of 45 non-drinkers in their 40s had prostatic hyperplasia. In the flushing group for this same age range, 51 drinkers (64.6\%) who had less than four drinks per week, 21 (77.8\%) of the drinkers who had four to eight drinks per week, and 25 (65.8\%) of the drinkers who had more than eight drinks per week had prostatic hyperplasia. Analysis using the chi-square test for trend in this group (flushing, 40s) showed that the incidence of prostatic hyperplasia had no statistically significant relation with the amount of alcohol consumption ( $\mathrm{P}=0.659)$.

Among the subjects in their 50s, 72 (87.8\%) of 82 non-drinkers had prostatic hyperplasia. In the flushing group of this age, 65 drinkers (70.7\%) who had less than four drinks per week, 27 drinkers (71.1\%) who had four to eight drinks per week, and 34 drinkers (69.4\%) who had more than eight drinks per week had prostatic hyperplasia. Analysis showed that the prevalence of prostatic hyperplasia was significantly lower among this group (flushing, 50s) than in non-drinkers $(\mathrm{P}=0.019)$ (Table 2). On multivariate logistic regression, confounding factors such as age, BMI, the amount of exercise, and smoking status were adjusted to calculate the risk of prostatic hyperplasia in drinkers compared to that in non-drinkers. The odds ratio (95\% confidence interval [CI]) was $0.38(0.16-0.86)$ for drinkers who had less than four drinks per week, 0.35 (0.13-0.95) for drinkers who had four to eight drinks per week, and 0.33 (0.13-0.84) for drinkers who had more than eight drinks per week, indicating that subjects in their 50s with facial flushing after drinking had a lower risk of prostatic hyperplasia compared to non-drinkers (Table 3).

Forty-three (81.1\%) of 53 non-drinkers in their 60 s had prostatic hyperplasia. Of the drinkers in this age group, 32 (84.2\%) who had less than four drinks per week, 14 (93.3\%) who had four to eight drinks per week, and 10 (76.9\%) who had more than eight drinks per week had prostatic hyperplasia. Analysis of the data using the chi-square test for trend showed no statistical significance $(\mathrm{P}=0.904)$ (Table 2).

\section{Risk of Prostatic Hyperplasia by Age Group Based on the Amount of Alcohol Consumption in the Non-Flushing Group} The non-flushing group was also analyzed according to the same age groups. The distribution of prostatic hyperplasia according to the weekly alcohol consumption for each age group was compared to that of the non-drinkers, and the difference was not statistically significant (Table 2). Using multivariate logistic regression, with adjustment for

Table 1. Characteristics of the subjects

\begin{tabular}{|c|c|c|c|}
\hline \multirow[b]{2}{*}{ Characteristic } & \multirow{2}{*}{$\begin{array}{l}\text { Non-drinkers } \\
\quad(n=180)\end{array}$} & \multicolumn{2}{|c|}{ Drinkers } \\
\hline & & $\begin{array}{l}\text { Flushing group } \\
\quad(n=389)\end{array}$ & $\begin{array}{l}\text { Non-flushing group } \\
\qquad(\mathrm{n}=388)\end{array}$ \\
\hline Age (y) & $54.8 \pm 7.6$ & $52.0 \pm 7.5^{\star}$ & $51.1 \pm 6.9^{*}$ \\
\hline Body mass index $\left(\mathrm{kg} / \mathrm{m}^{2}\right)$ & $24.7 \pm 3.4$ & $24.8 \pm 2.7$ & $24.6 \pm 2.8$ \\
\hline \multicolumn{4}{|l|}{ Smoking } \\
\hline Non-smoker & $78(43.3)$ & $112(28.8)$ & $124(32.0)$ \\
\hline Ex-smoker & $59(32.8)$ & $146(37.5)$ & $129(33.2)$ \\
\hline Smoker & $43(23.9)$ & $131(33.7)^{\dagger}$ & $135(34.8)^{\dagger}$ \\
\hline \multicolumn{4}{|l|}{ Exercise $^{\ddagger}$} \\
\hline None & $78(43.3)$ & $139(35.7)$ & $141(36.3)$ \\
\hline Irregular & $35(19.4)$ & 89 (22.9) & $105(27.1)$ \\
\hline Regular & $50(27.8)$ & $132(33.9)$ & $116(29.9)$ \\
\hline Every day & $17(9.4)$ & $29(7.5)$ & $26(6.7)$ \\
\hline \multicolumn{4}{|l|}{ Drinks/wk } \\
\hline $40-49$ & - & $7.9 \pm 9.7^{\star}$ & $11.1 \pm 11.1^{*}$ \\
\hline $50-59$ & - & $7.5 \pm 7.6^{\star}$ & $10.4 \pm 9.1^{*}$ \\
\hline $60-69$ & - & $7.3 \pm 9.9^{\star}$ & $7.5 \pm 10.3^{*}$ \\
\hline Prostate volume (g) & $26.3 \pm 8.9$ & $24.2 \pm 8.0^{\dagger}$ & $23.9 \pm 7.1^{\dagger}$ \\
\hline
\end{tabular}

Values are presented as mean \pm standard deviation or number (\%).

${ }^{*} P<0.001,{ }^{\dagger} P<0.01$ by the t-test with Bonferroni correlation or chi-square test compared with non-drinkers. ”Medium-to-high intensity exercise lasting more than 30 minutes: those who did not work out; worked out irregularly (one or two times a week); worked out regularly (three to five times a week); and worked out almost every day. ${ }^{\S 1}$ standard drink $=14 \mathrm{~g}$ of alcohol. 
Table 2. Relationship between alcohol consumption and prostatic hyperplasia in the flushing and non-flushing groups

\begin{tabular}{|c|c|c|c|c|}
\hline Drinks/wk & $\begin{array}{l}\text { No. of } \\
\text { patients }\end{array}$ & $\begin{array}{l}\text { Prostatic } \\
\text { hyperplasia }\end{array}$ & P-value & $\begin{array}{l}\text { Chi-square } \\
\text { trend }\end{array}$ \\
\hline \multicolumn{5}{|l|}{ Flushing group } \\
\hline \multicolumn{5}{|l|}{$40-49 y$} \\
\hline Non-drinkers & 45 & $29(64.4)$ & & 0.659 \\
\hline$\leq 4$ & 79 & $51(64.6)$ & $1.000^{\star}$ & \\
\hline$>4 \leq 8$ & 27 & $21(77.8)$ & $0.296^{\star}$ & \\
\hline$>8$ & 38 & $25(65.8)$ & $1.000^{*}$ & \\
\hline \multicolumn{5}{|l|}{$50-59 y$} \\
\hline Non-drinkers & 82 & 72 (87.8) & & 0.019 \\
\hline$\leq 4$ & 92 & 65 (70.7) & $0.009^{\star}$ & \\
\hline$>4 \leq 8$ & 38 & 27 (71.1) & $0.037^{\star}$ & \\
\hline$>8$ & 49 & 34 (69.4) & $0.012^{\star}$ & \\
\hline \multicolumn{5}{|l|}{$60-69 y$} \\
\hline Non-drinkers & 53 & $43(81.1)$ & & 0.904 \\
\hline$\leq 4$ & 38 & $32(84.2)$ & $0.785^{\star}$ & \\
\hline$>4 \leq 8$ & 15 & 14 (93.3) & $0.433^{\star}$ & \\
\hline$>8$ & 13 & $10(76.9)$ & $0.709^{\star}$ & \\
\hline \multicolumn{5}{|l|}{ Non-flushing group } \\
\hline \multicolumn{5}{|l|}{$40-49$ y } \\
\hline Non-drinkers & 45 & 29 (64.4) & & 0.433 \\
\hline$\leq 4$ & 66 & 45 (69.2) & $0.688^{\star}$ & \\
\hline$>4 \leq 8$ & 24 & $12(50.0)$ & $0.306^{\star}$ & \\
\hline$>8$ & 76 & $46(60.5)$ & $0.702^{\star}$ & \\
\hline \multicolumn{5}{|l|}{$50-59 y$} \\
\hline Non-drinkers & 82 & 72 (87.8) & & 0.534 \\
\hline$\leq 4$ & 58 & 46 (79.3) & $0.238^{\star}$ & \\
\hline$>4 \leq 8$ & 44 & $35(79.5)$ & $0.296^{\star}$ & \\
\hline$>8$ & 73 & 61 (83.6) & $0.495^{\star}$ & \\
\hline \multicolumn{5}{|l|}{$60-69 y$} \\
\hline Non-drinkers & 53 & 43 (81.1) & & 1.000 \\
\hline$\leq 4$ & 31 & $26(83.9)$ & $1.000^{\star}$ & \\
\hline$>4 \leq 8$ & 6 & $3(50.0)$ & $0.114^{\dagger}$ & \\
\hline$>8$ & 10 & $9(90.0)$ & $0.676^{\star}$ & \\
\hline
\end{tabular}

Values are presented as number (\%).

*By the chi-square test compared with non-drinkers. ${ }^{\dagger}$ By Fisher's exact test when the model included any cell with $n<5$.

confounding factors such as age, BMI, amount of exercise, and smoking status, the risk of prostatic hyperplasia in the non-flushing group compared to the non-drinkers was calculated. The odds ratio (95\% CI) for the group in their 40s were $1.37(0.60-3.14)$ for drinkers who had less than four drinks per week, $0.42(0.14-1.22)$ for drinkers who had four to eight drinks per week, and $0.84(0.37-1.91)$ for drinkers who had more than eight drinks per week. The odds ratios for the group in their 50s were 0.59 (0.23-1.52), 0.58 (0.21-1.63), and 0.85 (0.33-2.22), respectively, indicating that the odds ratio decreased with alcohol consumption; however, this was not statistically significant. The odds ratios of the non-flushing group in their 60s were 1.29 (0.36-4.61), 0.24 (0.04-1.69), and 3.07 (0.32-29.12), respectively, again showing no statistically significant difference (Table 3 ).
Table 3. Logistic regression analysis on prostatic hyperplasia risk according to alcohol intake in the flushing and non-flushing groups

\begin{tabular}{|c|c|c|}
\hline \multirow{2}{*}{ Drinks/wk } & \multicolumn{2}{|r|}{ Multivariate model } \\
\hline & P-value & Odds ratio* (95\% confidence interval) \\
\hline \multicolumn{3}{|l|}{ Flushing group } \\
\hline \multicolumn{3}{|l|}{$40-49$ y } \\
\hline Non-drinkers & & 1.00 \\
\hline$\leq 4$ & 0.79 & $1.11(0.50-2.48)$ \\
\hline$>4 \leq 8$ & 0.12 & $2.46(0.78-7.69)$ \\
\hline$>8$ & 0.72 & $1.19(0.46-3.06)$ \\
\hline \multicolumn{3}{|l|}{$50-59$ y } \\
\hline Non-drinkers & & 1.00 \\
\hline$\leq 4$ & 0.02 & $0.38(0.16-0.86)$ \\
\hline$>4 \leq 8$ & 0.04 & $0.35(0.13-0.95)$ \\
\hline$>8$ & 0.02 & $0.33(0.13-0.84)$ \\
\hline \multicolumn{3}{|l|}{$60-69$ y } \\
\hline Non-drinkers & & 1.00 \\
\hline$\leq 4$ & 0.77 & $1.20(0.37-3.92)$ \\
\hline$>4 \leq 8$ & 0.47 & $2.32(0.24-22.79)$ \\
\hline$>8$ & 0.95 & $0.95(0.19-4.65)$ \\
\hline \multicolumn{3}{|l|}{ Non-flushing group } \\
\hline \multicolumn{3}{|l|}{$40-49$ y } \\
\hline Non-drinkers & & 1.00 \\
\hline$\leq 4$ & 0.46 & $1.37(0.60-3.14)$ \\
\hline$>4 \leq 8$ & 0.11 & $0.42(0.14-1.22)$ \\
\hline$>8$ & 0.68 & $0.84(0.37-1.91)$ \\
\hline \multicolumn{3}{|l|}{$50-59$ y } \\
\hline Non-drinkers & & 1.00 \\
\hline$\leq 4$ & 0.28 & $0.59(0.23-1.52)$ \\
\hline$>4 \leq 8$ & 0.30 & $0.58(0.21-1.63)$ \\
\hline$>8$ & 0.74 & $0.85(0.33-2.22)$ \\
\hline \multicolumn{3}{|l|}{$60-69$ y } \\
\hline Non-drinkers & & 1.00 \\
\hline$\leq 4$ & 0.69 & $1.29(0.36-4.61)$ \\
\hline$>4 \leq 8$ & 0.15 & $0.24(0.04-1.69)$ \\
\hline$>8$ & 0.33 & $3.07(0.32-29.12)$ \\
\hline
\end{tabular}

${ }^{\star}$ Adjusted for age, body mass index, exercise, and smoking state.

\section{DISCUSSION}

This study investigated the relationship between prostatic hyperplasia and alcohol consumption, based on the presence or absence of facial flushing after drinking. The current study demonstrated that drinkers in their 50s with facial flushing have a lower risk of developing prostatic hyperplasia than do non-drinkers.

Male hormones need to be supplied consistently in order to develop the prostate and to maintain the function of secretion normally. Men who are castrated before adolescence or who genetically lack androgens experience a rapid cell transformation of the prostatic tissues, which eventually leads to shrinking of the prostate; therefore, they do not develop benign prostatic hyperplasia. In castrated mice, the prostate regrows when male hormones are injected. ${ }^{15-18)}$ Androgens are therefore definitely important in the occurrence of prostatic hyperplasia.

The risk of benign prostatic hyperplasia in terms of alcohol consumption, age, race, BMI, and the extent of exercise has been investi- 
gated in previous studies. One of those studies showed that when nondrinkers were compared to drinkers who consumed at least $740 \mathrm{~mL}$ (25 oz) of alcohol per month, the risk of benign prostatic hyperplasia decreased to 0.64 (CI, 0.52 to 0.78 ) for drinkers. ${ }^{19)}$ This inverse relationship between alcohol consumption and benign prostatic hyperplasia showed the same pattern for different types of alcohol, such as wine, beer, and hard liquor. ${ }^{20)}$

The prostate is highly dependent on male hormones, and many studies have reported that alcohol changes the concentration of blood testosterone, a male hormone. When nine men were asked to consume $1.3 \mathrm{~g} / \mathrm{kg}$ of alcohol around the same time each day for seven days or the same amount of alcohol all at once within 30 minutes, all of them showed hormonal changes and their testosterone level decreased. ${ }^{21)}$ In another study, healthy men were asked to consume a set amount of alcohol for four weeks along with balanced meals to examine the effect of alcohol on their testosterone level; the result showed that temporary alcohol consumption and repetitive alcohol consumption lowered the concentration of blood testosterone. ${ }^{22)}$ Moreover, men with alcoholic liver cirrhosis tended to have hypogonadism or become feminized; in such cases, decreased testosterone levels and the resultant increase in estrogen levels lead to a lower risk of benign prostatic hyperplasia, based on autopsy results. ${ }^{23,24)}$ However, in other experiments androgens did not play a role as a growth factor of cultured prostate epithelial cells. ${ }^{25)}$

Compared with various studies of the impact of alcohol consumption on benign prostatic hyperplasia, the current study is unique in that it divided drinkers into those with facial flushing and those without facial flushing. In this study, drinkers in their 50s with facial flushing showed a decrease in the risk of prostatic hyperplasia relative to non-drinkers. Drinkers with facial flushing after alcohol consumption have an excessive amount of acetaldehyde. In such individuals, we expect the higher concentration of aldehyde due to low ALDH2 activity to be related to a lower risk of benign prostatic hyperplasia. However, this finding conflicts with that of a study that reported aldehyde creation to be significantly increased in patients with benign prostatic hyperplasia. ${ }^{26)}$ More studies are clearly needed, since only in a specific age group, men in their 50s, did we find an inverse relationship between drinking-associated facial flushing and prostatic hyperplasia. Additionally, further research is needed into ALDH2 activity and hormonal conditions that could explain the lower prevalence of prostatic hyperplasia in men who experience facial flushing after drinking.

This study had some limitations. First, it was difficult to find a causal relationship as the study was a cross-sectional study. Second, the sample was taken from one regional hospital in Daejeon; therefore, it is unlikely to represent the entire population of Korean men. Lastly, the study may be biased because only those who are highly interested in their health would have participated in this study.

Despite such limitations, the present study is significant in that it investigated the relationship between alcohol consumption and prostatic hyperplasia based on the presence of facial flushing after alcohol consumption. In addition, our findings suggest that the presence of al- cohol-related facial flushing must be considered together with alcohol consumption by the family physician in daily clinical practice.

\section{CONFLICT OF INTEREST}

No potential conflict of interest relevant to this article was reported.

\section{REFERENCES}

1. Berry SJ, Coffey DS, Walsh PC, Ewing LL. The development of human benign prostatic hyperplasia with age. J Urol 1984;132:474-9.

2. Lee E, Yoo KY, Kim Y, Shin Y, Lee C. Prevalence of lower urinary tract symptoms in Korean men in a community-based study. Eur Urol 1998;33:17-21.

3. Lee H, Hwa JS, Choi BS, Choi CW, Kim JT, Jung SH, et al. Correlation between age, prostatic volume and voiding symptoms in randomly selected Korean over age 60. Korean J Urol 1994;35:1208-13.

4. Ozden C, Ozdal OL, Urgancioglu G, Koyuncu H, Gokkaya S, Memis A. The correlation between metabolic syndrome and prostatic growth in patients with benign prostatic hyperplasia. Eur Urol 2007;51:199-203.

5. Kim JH, Shim BS, Hong YS. The relating factors of metabolic syndrome to benign prostatic hyperplasia. Korean J Urol 2005;46:1046-50.

6. Platz EA, Rimm EB, Kawachi I, Colditz GA, Stampfer MJ, Willett WC, et al. Alcohol consumption, cigarette smoking, and risk of benign prostatic hyperplasia. Am J Epidemiol 1999;149:106-15.

7. Lee E, Park MS, Shin C, Lee H, Yoo K, Kim Y, et al. A high-risk group for prostatism: a population-based epidemiological study in Korea. Br J Urol 1997;79:736-41.

8. Mendelson JH, Mello NK, Ellingboe J. Effects of acute alcohol intake on pituitary-gonadal hormones in normal human males. J Pharmacol Exp Ther 1977;202:676-82.

9. Caine M. The present role of alpha-adrenergic blockers in the treatment of benign prostatic hypertrophy. J Urol 1986;136:1-4.

10. Ohta S, Ohsawa I, Kamino K, Ando F, Shimokata H. Mitochondrial ALDH2 deficiency as an oxidative stress. Ann N Y Acad Sci 2004;1011: 36-44.

11. Wang Y, Zhang Y, Zhang J, Tang X, Qian Y, Gao P, et al. Association of a functional single-nucleotide polymorphism in the ALDH2 gene with essential hypertension depends on drinking behavior in a Chinese Han population. J Hum Hypertens 2013;27:181-6.

12. Seok H, Yoo KH, Kim YO, Chung JH. Association of a missense ALDH2 single nucleotide polymorphism (glu504Lys) with benign prostate hyperplasia in a Korean population. Int Neurourol J 2013;17:168-73.

13. Guo R, Ren J. Alcohol and acetaldehyde in public health: from marvel to menace. Int J Environ Res Public Health 2010;7:1285-301.

14. Garraway WM, Collins GN, Lee RJ. High prevalence of benign prostatic hypertrophy in the community. Lancet 1991;338:469-71.

15. Bruchovsky N, Lesser B, Van Doorn E, Craven S. Hormonal effects on cell proliferation in rat prostate. Vitam Horm 1975;33:61-102.

16. Joseph MA, Harlow SD, Wei JT, Sarma AV, Dunn RL, Taylor JM, et al. Risk factors for lower urinary tract symptoms in a population-based sample of African-American men. Am J Epidemiol 2003;157:906-14.

17. McConnell JD, Roehrborn CG, Bautista OM, Andriole GL Jr, Dixon CM, Kusek JW, et al. The long-term effect of doxazosin, finasteride, 
and combination therapy on the clinical progression of benign prostatic hyperplasia. N Engl J Med 2003;349:2387-98.

18. Thompson IM, Goodman PJ, Tangen CM, Lucia MS, Miller GJ, Ford LG, et al. The influence of finasteride on the development of prostate cancer. N Engl J Med 2003;349:215-24.

19. Chyou PH, Nomura AM, Stemmermann GN, Hankin JH. A prospective study of alcohol, diet, and other lifestyle factors in relation to obstructive uropathy. Prostate 1993;22:253-64.

20. Crispo A, Talamini R, Gallus S, Negri E, Gallo A, Bosetti C, et al. Alcohol and the risk of prostate cancer and benign prostatic hyperplasia. Urology 2004;64:717-22.

21. Ida Y, Tsujimaru S, Nakamaura K, Shirao I, Mukasa H, Egami H, et al. Effects of acute and repeated alcohol ingestion on hypothalamic-pituitary-gonadal and hypothalamic-pituitary-adrenal functioning in normal males. Drug Alcohol Depend 1992;31:57-64.

22. Gordon GG, Altman K, Southren AL, Rubin E, Lieber CS. Effect of al- cohol (ethanol) administration on sex-hormone metabolism in normal men. N Engl J Med 1976;295:793-7.

23. Green GR. Mechanism of hypogonadism in cirrhotic males. Gut 1977;18:843-53.

24. Frea B, Annoscia S, Stanta G, Lozzi C, Carmignani G. Correlation between liver cirrhosis and benign prostatic hyperplasia: a morphological study. Urol Res 1987;15:311-4.

25. McKeehan WL, Adams PS, Rosser MP. Direct mitogenic effects of insulin, epidermal growth factor, glucocorticoid, cholera toxin, unknown pituitary factors and possibly prolactin, but not androgen, on normal rat prostate epithelial cells in serum-free, primary cell culture. Cancer Res 1984;44:1998-2010.

26. Merendino RA, Salvo F, Saija A, Di Pasquale G, Tomaino A, Minciullo PL, et al. Malondialdehyde in benign prostate hypertrophy: a useful marker? Mediators Inflamm 2003;12:127-8. 